\title{
The expression of microRNA-23a regulates acute myocardial infarction in patients and in vitro through targeting PTEN
}

\author{
SHENGLI LI ${ }^{1 *}$, JIE REN $^{2 *}$ and QIANMEI SUN ${ }^{1}$ \\ ${ }^{1}$ Department of Internal Medicine, Beijing Chaoyang Hospital, Capital Medical University, Beijing 100022; \\ ${ }^{2}$ Department of Medical Cardiology, The First Affiliated Hospital of Xi'an Jiao Tong University, \\ Xi'an, Shaanxi 710061, P.R. China
}

Received July 28, 2016; Accepted September 11, 2017

DOI: $10.3892 / \mathrm{mmr} .2018 .8640$

\begin{abstract}
Cardiovascular disease is responsible for one of the highest rates of fatality worldwide. The present study investigated the presence and influence of microRNA (miRNA)-23a in the regulation of acute myocardial infarction (AMI). A total of 6 patients with AMI and 6 normal volunteers without myocardial disease were included, and blood samples were taken to analyze the expression of miRNA-23a by reverse transcription-quantitative polymerase chain reaction. miRNA-23a expression in patients with AMI was downregulated compared with the normal group. In H9C2 cells treated with $\mathrm{H}_{2} \mathrm{O}_{2}$, upregulation of miRNA-23a expression increased the superoxide dismutase, glutathione and catalase activity levels, and suppressed the malonaldehyde activity level, as determined by ELISA. Western blot analysis and a caspase-3 substrate assay demonstrated that upregulation of miRNA-23a expression suppressed the Bcl-2-associated X (Bax)/Bcl-2 protein expression ratio, caspase-3 activity level and tumor suppressor p53 (p53) protein expression in $\mathrm{H}_{2} \mathrm{O}_{2}$-induced H9C2 cells. Furthermore, downregulation of phosphatase and tensin homolog (PTEN), by the PTEN inhibitor bpV(HOpic), increased miRNA-23a expression and suppressed the $\mathrm{Bax} / \mathrm{Bcl}-2$ protein expression ratio, caspase-3 activity level and p53 protein expression in $\mathrm{H}_{2} \mathrm{O}_{2}$-induced $\mathrm{H} 9 \mathrm{C} 2$ cells. Therefore, the results of the present study indicate that the expression of miRNA-23a may regulate AMI through targeting PTEN in patients and in vitro, and PTEN/miRNA-23a may therefore be potential targets for the clinical treatment of AMI.
\end{abstract}

Correspondence to: Professor Qianmei Sun, Department of Internal Medicine, Beijing Chaoyang Hospital, Capital Medical University, 8 Gongti South Road, Beijing 100022, P.R. China

E-mail: sibu1999062052@126.com

*Contributed equally

Key words: microRNA-23a, acute myocardial infarction, phosphatase and tensin homolog, apoptosis

\section{Introduction}

Cardiovascular disease is one of the diseases with the highest fatality rates worldwide. In the United States, $\sim 1 / 6$ th of the annual death toll is associated with coronary heart disease and associated diseases with myocardial injury (1). Acute myocardial infarction (AMI) results in ventricular remodeling that causes the deterioration of heart function leading to heart failure (2). Myocardial fibrosis leads to decreased myocardial contractility and subsequent ventricular systolic dysfunction (3).

Myocardial remodeling, including the remodeling of myocardial cells and the extracellular matrix (ECM), is key for the transformation process of heart disease to heart failure (4). Previously, it was hypothesized that the function of the ECM is constant and is primarily responsible for connection, support and protection (5). Recently, a study demonstrated that ECM is in an active state and is actively involved in intracellular and extracellular signaling and the maintenance of cardiac structure and function (5). Therefore, ECM remodeling serves an important role in the initiation and development of heart failure.

AMI is a cardiovascular disease with serious implications for human health. It may lead to heart failure and a number of other conditions with poor prognoses (6). Myocardial fibrosis is an important pathophysiological alteration following AMI. It is activated as a result of multiple fibrosis-associated factors and leads to interstitial cell hyperplasia (7). Myocardial fibrosis increases cardiac stiffness, decreases diastolic systolic function and alters the normal structure of cardiac electrophysiology, which leads to arrhythmia and potentially even sudden death (8).

Phosphatase and tensin homolog (PTEN) is a tumor suppressor that was discovered in 1997. The genes that encode PTEN are located at 10q23.3 and encoded by a dual specificity phosphatase consisting of 403 amino acids (9). PTEN is a dual specificity phosphatase with lipid phosphatase and protein phosphatase activity (9). PTEN enables the secondary messenger produced by phosphatidylinositol 3-kinase (PI3K) to phosphorylate and prevent protein kinase $\mathrm{B}$ (Akt) from being activated and inhibits its downstream biological functions (10). It has been reported that PTEN is associated with ischemic heart disease (11). Blocking the 
PTEN signaling pathway confirmed that PTEN influences myocardial ischemic injury events and reduces the death of myocardial cells (11). However, studies on myocardial ischemic injury in which one or several genes that regulate cardiomyocyte apoptosis through PTEN are investigated have not previously been performed (11).

MicroRNAs (miRNAs) are a group of non-coding RNAs that are endogenous, short ( 22 bp) (12) and are highly conserved in sequence between species. Currently, there are $\sim 1,400$ types of miRNAs in humans and novel miRNA are frequently identified. Each type of miRNA serves an important role in the transcription processes in the body by regulating the expression of various target genes (13). miRNA influences cells in numerous ways, including the regulation of cellular apoptosis and necrosis, and these two mechanisms are of great importance in ventricular remodeling during the developmental phase of AMI. The results of the present study help to elucidate the presence and role of miRNA-23a in the regulation of AMI.

\section{Materials and methods}

Patient selection and blood collection. The present study was approved by the Regional Ethics Committee of Beijing Chaoyang Hospital (Beijing, China) and all patients involved gave their written informed consent. A total of 6 patients with AMI (aged 57-66 years, male) and 6 normal volunteers (aged 23-28 years, male) without myocardial disease were recruited between July 2015 and August 2015 from the Department of Internal Medicine, Beijing Chaoyang Hospital. Between 8:00 and 10:00 a.m., blood samples $(5 \mathrm{ml})$ were collected and centrifuged at $2,000 \mathrm{xg}$ for $10 \mathrm{~min}$ at $4^{\circ} \mathrm{C}$ to be stored at $-80^{\circ} \mathrm{C}$.

Cell culture. The H9C2 cell line was purchased from the Type Culture Collection of Chinese Academy of Sciences (Shanghai, China) and cultured in Dulbecco's modified Eagle medium (Gibco; Thermo Fisher Scientific, Inc., Waltham, MA, USA) with $10 \%$ fetal bovine serum (Hyclone; GE Healthcare Life Sciences, Logan, UT, USA), $100 \mathrm{U} / \mathrm{ml}$ penicillin and $100 \mu \mathrm{g} / \mathrm{ml}$ streptomycin (Beyotime Institute of Biotechnology, Haimen, China) in a humidified atmosphere containing $5 \% \mathrm{CO}_{2}$ at $37^{\circ} \mathrm{C}$.

Cell transfection. The miRNA-23a mimic (5'-ggceggctg gggttcctggg-3') and the negative controls (5'-CCCCCCCCC C-3') were purchased from MyGenostics, Inc., (Beijing, China). Following $6 \mathrm{~h}$ of incubation at $37^{\circ} \mathrm{C}$ with Dulbecco's modified Eagle medium (Invitrogen; Thermo Fisher Scientific, Inc.) supplemented with fetal bovine serum (Invitrogen; Thermo Fisher Scientific, Inc.), cells $\left(1 \times 10^{6}\right)$ were transfected with miRNA-23a mimic (50 nM) and negative controls $(50 \mathrm{nM})$ for $48 \mathrm{~h}$ using Lipofectamine ${ }^{\circledR} 2000$ (Invitrogen; Thermo Fisher Scientific, Inc.). Subsequently, $4 \mathrm{~h}$ following transfection of $\mathrm{H} 9 \mathrm{C} 2$ cells with miRNA-23a, the cells were treated with $600 \mu \mathrm{M} \mathrm{H}_{2} \mathrm{O}_{2}$ (Sigma-Aldrich; Merck KGaA, Darmstadt, Germany) with or without the PTEN inhibitor, bpV(HOpic) (1 $\mu \mathrm{M}$; cat. no. sc-33022; Santa Cruz Biotechnology, Inc., Dallas, TX, USA), for $2 \mathrm{~h}$ at $37^{\circ} \mathrm{C}$. Cells that were transfected with negative controls received treatment with $\mathrm{H}_{2} \mathrm{O}_{2}$ only.
Reverse transcription-quantitative polymerase chain reaction (RT-qPCR). Total RNA was isolated from blood samples or cell samples using TRIzol ${ }^{\mathrm{TM}}$ reagent (Invitrogen; Thermo Fisher Scientific, Inc.). Total RNA (0.5-1 $\mu \mathrm{g})$ was reverse transcribed into cDNA using an iScript ${ }^{\mathrm{TM}}$ cDNA synthesis kit (Bio-Rad Laboratories, Inc., Hercules, CA, USA) at $37^{\circ} \mathrm{C}$ for $60 \mathrm{~min}$ and $85^{\circ} \mathrm{C}$ for $5 \mathrm{~min}$. qPCR was performed using Takara SYBR Premix Ex Taq ${ }^{\mathrm{TM}}$ (Tli RNase H Plus; Takara Bio, Inc., Otsu, Japan) on a CFX96 ${ }^{\mathrm{TM}}$ Real-Time PCR Detection System (Bio-Rad Laboratories, Inc.) with the following thermocycling conditions: $95^{\circ} \mathrm{C}$ for $10 \mathrm{~min}$, followed by 40 cycles of $95^{\circ} \mathrm{C}$ for $25 \mathrm{sec}, 60^{\circ} \mathrm{C}$ for $30 \mathrm{sec}$ and $72^{\circ} \mathrm{C}$ for $30 \mathrm{sec}$. The primers used for qPCR were as follows: miR-23a forward, 5'-GGGGGG GGATCACATTGCCA-3' and reverse, 5'-CAGTGCAGGGTC CGAGGT-3'; and U6 forward, 5'-GCTTCGGCAGCACAT ATACTAAAAT and reverse, 5'-CGCTTCACGAATTTG CGTGTCAT-3'. The relative expression level of miRNA-23a was calculated by the $2^{-\Delta \Delta \mathrm{Cq}}$ method (14).

Measurement of oxidative stress. H9C2 cells ( $1 \times 10^{5}$ cells) transfected with miRNA-23a or negative controls were treated with $600 \mu \mathrm{M} \mathrm{H}_{2} \mathrm{O}_{2}$ with or without $1 \mu \mathrm{M} \mathrm{bpV(HOpic)} \mathrm{for} 2 \mathrm{~h}$. Subsequently, H9C2 cells were lysed in radioimmunoprecipitation buffer (RIPA; Nanjing KeyGen Biotech Co., Ltd., Nanjing, China) containing phenylmethanesulfonyl fluoride (PMSF; 1:100; Nanjing KeyGen Biotech Co., Ltd.). Total proteins were quantified with a bicinchoninic assay (BCA) protein kit (Beyotime Institute of Biotechnology). Total protein (10-20 $\mu \mathrm{g}$ ) was incubated with superoxide dismutase (SOD, cat. no. A001-3), glutathione (GSH; cat. no. A006-2), catalase (CAT; cat. no. A007-1-1) and malondialdehyde (MDA, cat. no. A003-1) ELISA kits (Nanjing Jiancheng Bioengineering Institute, Nanjing, China). Absorbance was measured at $450 \mathrm{~nm}$.

Measurement of caspase-3 activity level. H9C2 cells ( $1 \times 10^{5}$ cells) transfected with miRNA-23a or negative controls were treated with $600 \mu \mathrm{M} \mathrm{H}_{2} \mathrm{O}_{2}$ with or without $1 \mu \mathrm{M}$ bpV(HOpic) for $2 \mathrm{~h}$. Subsequently, H9C2 cells were lysed in RIPA buffer containing PMSF (1:100). Total proteins were quantified with a BCA protein assay kit. A total of $10 \mu \mathrm{g}$ total protein was incubated with the caspase-3 substrate Ac-DEVD-pNA (2 mM; Beyotime Institute of Biotechnology) for $2 \mathrm{~h}$ at $37^{\circ} \mathrm{C}$. Absorbance was measured at $405 \mathrm{~nm}$.

Western blot analysis. H9C 2 cells $\left(1 \times 10^{5}\right.$ cells) transfected with miRNA-23a or negative controls were treated with $600 \mu \mathrm{M}$ $\mathrm{H}_{2} \mathrm{O}_{2}$ with or without $1 \mu \mathrm{M} \mathrm{bpV(HOpic)} \mathrm{for} 2 \mathrm{~h}$. Subsequently, H9C2 cells were lysed in RIPA buffer containing PMSF $(1: 100)$. Total proteins were quantified with a BCA protein assay kit. A total of 50-60 $\mu \mathrm{g}$ total protein was subjected to $10 \%$ SDS-PAGE and transferred onto polyvinylidene difluoride membranes (Bio-Rad Laboratories, Inc.). Membranes were blocked with $5 \%$ non-fat milk for $1 \mathrm{~h}$ at $37^{\circ} \mathrm{C}$ and then probed with primary antibodies against Bcl-2-associated X (Bax; cat. no. A2211; 1:2,000; ABclonal Biotech Co., Ltd., Woburn, MA, USA), Bcl-2 (cat. no. A0208; 1:2,000; ABclonal Biotech Co., Ltd.), tumor suppressor p53 (p53; cat. no. AP0464; 1:1,000; ABclonal Biotech Co., Ltd.) and GAPDH (cat. no. A0080; 1:2,000; ABclonal Biotech Co., Ltd.) overnight at $4^{\circ} \mathrm{C}$. 
Following incubation with horseradish peroxidase-conjugated goat anti-rabbit IgG antibodies $(1 ; 10,000$; cat. no. HSA0003; Shanghai Bioon Biotechnology Co., Ltd., Shanghai, China) and anti-mouse secondary antibodies (1:5,000; cat. no. sc-2020; Santa Cruz Biotechnology, Inc.) for $1 \mathrm{~h}$ at room temperature, Clarity Max $^{\mathrm{TM}}$ Western ECL Substrate (cat. no. 1705062; Bio-Rad Laboratories, Inc.) was used for visualization. Protein bands were visualized using Image-ProPlus 6.0 software (Media Cybernetics, Inc., Rockville, MD, USA).

Statistical analysis. The results are presented as the mean \pm standard deviation. All data were analyzed with an independent-samples Student t-test or one-way analysis of variance test followed by Bonferroni's tests using SPSS software (version 17.0; SPSS, Inc., Chicago, IL, USA). P $<0.05$ was considered to indicate a statistically significant difference.

\section{Results}

Expression of miRNA-23a in patients with AMI. miRNA-23a expression was analyzed in patients with AMI and healthy volunteers. The results of RT-qPCR demonstrated that miRNA-23a expression in patients with AMI was significantly downregulated compared with the healthy volunteer group $(\mathrm{P}<0.01 ;$ Fig. 1$)$.

Expression of miRNA-23a in vitro in AMI. In addition, the miRNA-23a mimic was transfected into H9C2 cells, which promoted miRNA-23a expression in $\mathrm{H} 9 \mathrm{C} 2$ cells. Transfection of the miRNA-23a mimic in $\mathrm{H}_{2} \mathrm{O}_{2}$-treated $\mathrm{H} 9 \mathrm{C} 2$ cells significantly increased the expression of miRNA-23a, compared with the negative control group ( $\mathrm{P}<0.01$; Fig. 2).

Effect of miRNA-23a expression on oxidative stress in vitro in AMI. To investigate the functional effect of miRNA-23a in $\mathrm{H} 9 \mathrm{C} 2$ cells treated with $\mathrm{H}_{2} \mathrm{O}_{2}$, ELISAs were conducted to analyze levels of oxidative stress markers. There was a significant increase in the activity of SOD, GSH and CAT, and a decrease in the activity of MDA, in miRNA-23a-overexpressing $\mathrm{H} 9 \mathrm{C} 2$ cells treated with $\mathrm{H}_{2} \mathrm{O}_{2}$ compared with the negative control group $(\mathrm{P}<0.01$; Fig. 3$)$.

Effect of miRNA-23a expression on apoptosis in vitro in AMI. To investigate the functional effect of miRNA-23a on apoptosis in $\mathrm{H}_{2} \mathrm{O}_{2}$-treated $\mathrm{H} 9 \mathrm{C} 2$ cells, a commercial ELISA kit was employed to analyze caspase-3 activity. As demonstrated in Fig. 4A, in the miRNA-23a-overexpressing $\mathrm{H} 9 \mathrm{C} 2$ cells treated with $\mathrm{H}_{2} \mathrm{O}_{2}$, the caspase-3 activity was significantly decreased compared with the negative control group. In addition, the $\mathrm{Bax} / \mathrm{Bcl}-2$ and 553 protein expression was significantly decreased in miRNA-23a-overexpressing $\mathrm{H} 9 \mathrm{C} 2$ cells treated with $\mathrm{H}_{2} \mathrm{O}_{2}$ compared with the negative control group ( $\mathrm{P}<0.01$; Fig. 4B-D).

PTEN inhibitor effect on the in vitro expression of miRNA-23a in AMI. In order to investigate the association between miRNA-23a and PTEN expression in AMI, the PTEN inhibitor bpV(HOpic) was added to miRNA-23a-overexpressing $\mathrm{H} 9 \mathrm{C} 2$ cells. In the miRNA-23a-overexpressing $\mathrm{H} 9 \mathrm{C} 2$ cells treated with $\mathrm{H}_{2} \mathrm{O}_{2}$, the PTEN inhibitor significantly increased miRNA-23a expression, compared with the miRNA-23a-overexpressing group alone $(\mathrm{P}<0.01$; Fig. 5).

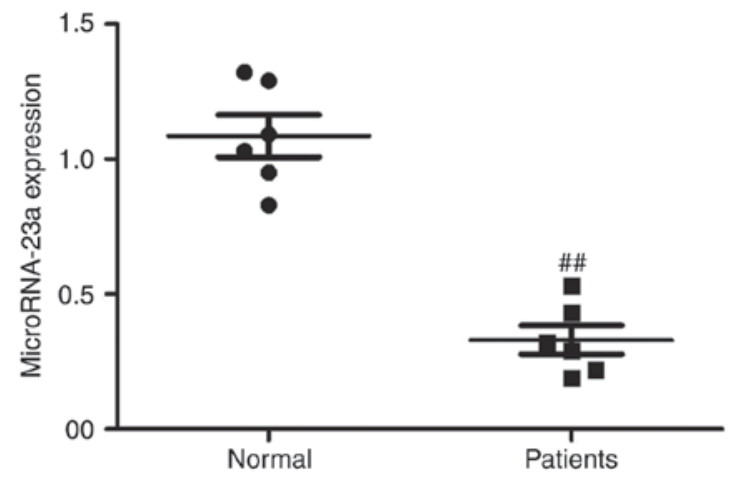

Figure 1. Expression of miRNA-23a in patients with acute myocardial infarction. ${ }^{\# \#} \mathrm{P}<0.01$ vs. normal group. miRNA, microRNA.

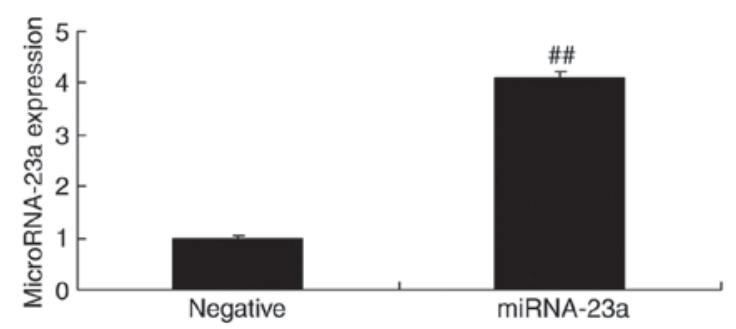

Figure 2. Expression of miRNA-23a in an in vitro model of acute myocardial infarction. ${ }^{\# \#} \mathrm{P}<0.01$ vs. negative control group. miRNA, microRNA.

Effect of PTEN inhibitor on in vitro oxidative stress in AMI. In order to investigate the effect of PTEN on oxidative stress in vitro in AMI, miRNA-23a-overexpressing $\mathrm{H} 9 \mathrm{C} 2$ cells were treated with $\mathrm{H}_{2} \mathrm{O}_{2}$. There was a significant increase in the activities of SOD, GSH and CAT, and a decrease of MDA content, compared with miRNA-23a-overexpressing $\mathrm{H} 9 \mathrm{C} 2$ cells treated with $\mathrm{H}_{2} \mathrm{O}_{2}$ alone ( $\mathrm{P}<0.01$; Fig. 6).

Effect of PTEN inhibitor on apoptosis in AMI. The effect of PTEN on in vitro on apoptosis in AMI was investigated. As demonstrated in Fig. 7, the downregulation of PTEN significantly suppressed $\mathrm{Bax} / \mathrm{Bcl}-2$ and $\mathrm{p} 53$ protein expression, and caspase-3 activity level, in miRNA-23a-overexpressing H9C2 cells treated with $\mathrm{H}_{2} \mathrm{O}_{2}$, compared with the miRNA-23a-overexpressing $\mathrm{H} 9 \mathrm{C} 2$ cells treated with $\mathrm{H}_{2} \mathrm{O}_{2}$ alone $(\mathrm{P}<0.01)$.

\section{Discussion}

With rapid socioeconomic development and improvements in living standards, and the alteration of modern lifestyles, the incidence of cardiovascular and cerebrovascular disease is increasing (15). The high morbidity rate and high case-fatality rate have serious effects on the physical and mental health of individuals (16). In China, the case-fatality rate of cardiocerebral vascular diseases is the second largest following malignant tumors (17). Solutions to the relevant problems are urgently required, such as methods that allow more in-depth research into the pathogenesis of cardiovascular and cerebrovascular diseases, and the development of more effective and safer clinical drugs (18).

Apoptosis is a form of programmed cell death. In the acute period of myocardial infarction, apoptosis is involved in 
A

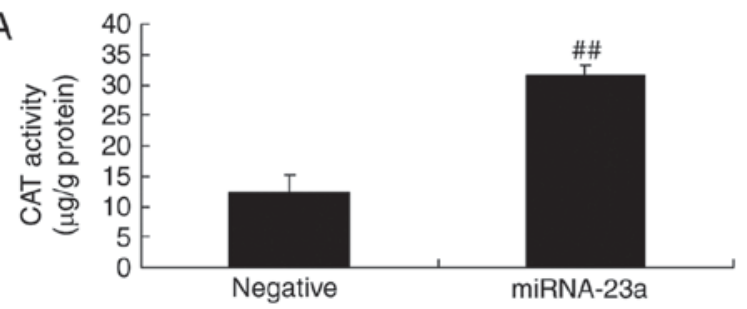

C

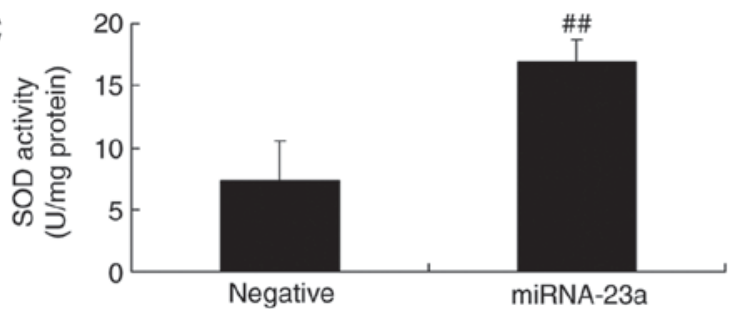

B

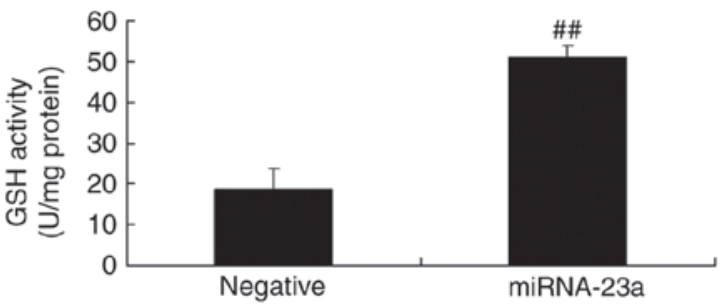

D

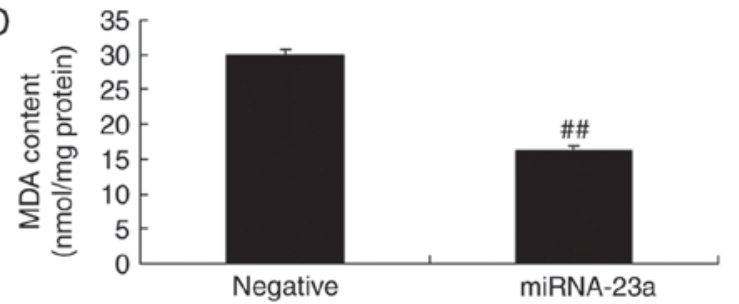

Figure 3. Effect of miRNA-23a expression on oxidative stress in an in vitro model of AMI. The effect of the expression of miRNA-23a on (A) CAT, (B) GSH and (C) SOD activity levels, and (D) MDA levels, in an in vitro model of AMI. ${ }^{\# /} \mathrm{P}<0.01$ vs. negative control group. miRNA, microRNA; AMI, acute myocardial infarction; CAT, catalase; GSH, glutathione; SOD, superoxide dismutase; MDA, malondialdehyde.

A

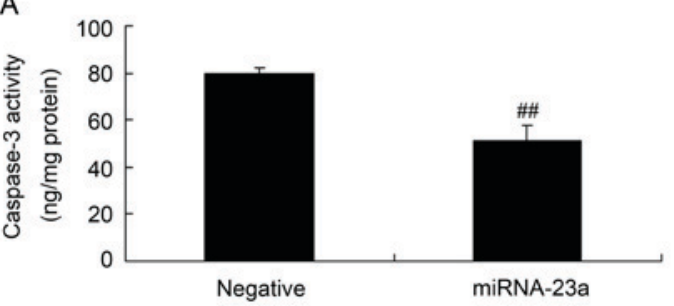

C

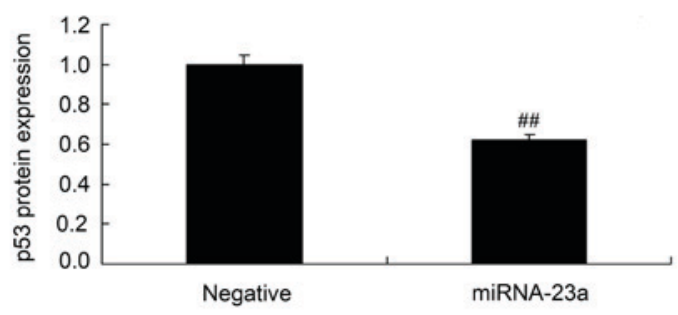

B

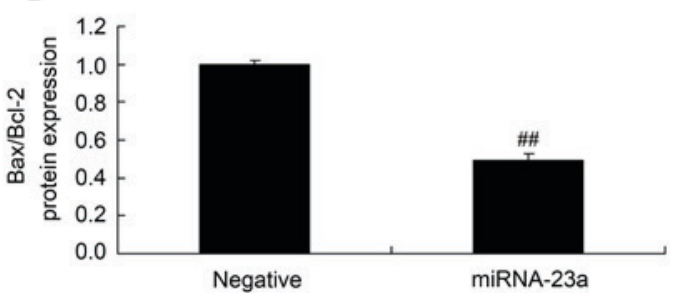

D

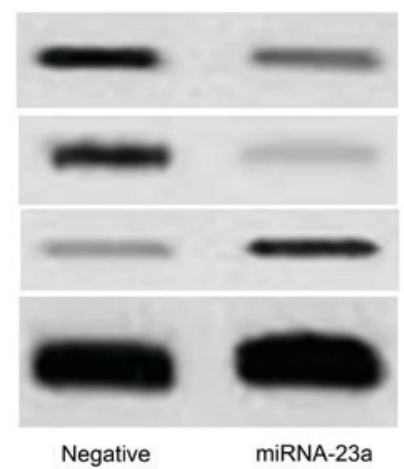

p53

Bax

Bcl-2

GAPDH

Figure 4. Effect of miRNA-23a expression on apoptosis in an in vitro model of AMI. (A) Quantitative analysis of the effect of miRNA-23a expression on caspase-3 activity in an in vitro model of AMI. Densitometric and statistical analysis of (B) Bax/Bcl-2 protein expression ratio and (C) p53 protein expression. (D) Representative western blot images for Bax, Bcl-2 and 53 protein expression in an in vitro model of AMI. ${ }^{\# \#} \mathrm{P}<0.01$ vs. negative control group. miRNA, microRNA; AMI, acute myocardial infarction; Bax, Bcl-2-associated X; p53, tumor suppressor p53.

the death of myocardial cells. It is similar to that myocardial has lost its improvement process in subacute or stale stage of myocardial infarction. miRNAs influence the regulation of cellular apoptosis and necrosis, and these two mechanisms are essential for the ventricular remodeling during the developmental phase of AMI (12). It has been demonstrated that there are numerous alterations in the expression of miRNAs in blood samples during the acute stage of AMI (19). If the association between miRNA expression and AMI could be elucidated, molecular markers may be identified for early clinical diagnosis of AMI to improve the survival rate of patients with AMI (20). Therefore, a number of studies in

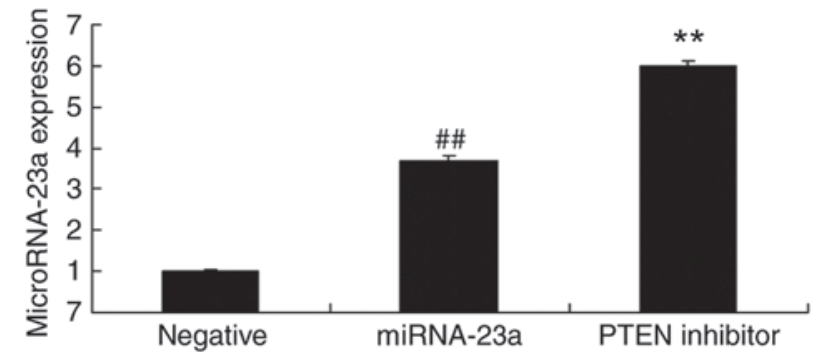

Figure 5. PTEN inhibitor effects on the miRNA-23a expression in an in vitro model of acute myocardial infarction. ${ }^{\# \#} \mathrm{P}<0.01$ vs. negative control group; ${ }^{* *} \mathrm{P}<0.01$ vs. miRNA-23a group. PTEN, phosphatase and tensin homolog; miRNA, microRNA. 

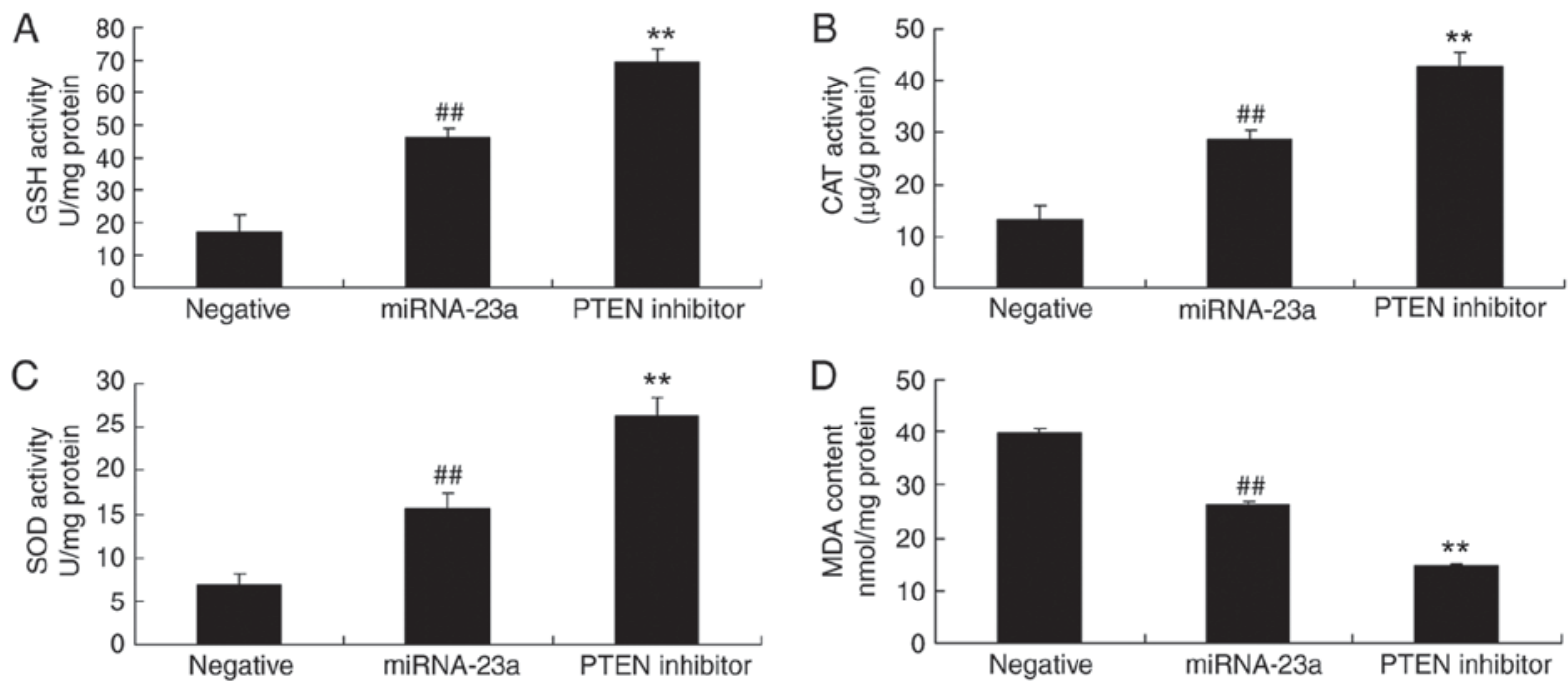

Figure 6. Effects of a PTEN inhibitor on oxidative stress in an in vitro model of AMI. Effects of a PTEN inhibitor on (A) GSH, (B) CAT and (C) SOD activity, and (D) MDA levels, in an in vitro model of AMI. ${ }^{\# \#} \mathrm{P}<0.01$ vs. negative control group; ${ }^{* *} \mathrm{P}<0.01 \mathrm{vs}$. miRNA-23a group. PTEN, phosphatase and tensin homolog; AMI, acute myocardial infarction; GSH, glutathione; CAT, catalase; SOD, superoxide dismutase; MDA, malondialdehyde; miRNA, microRNA.

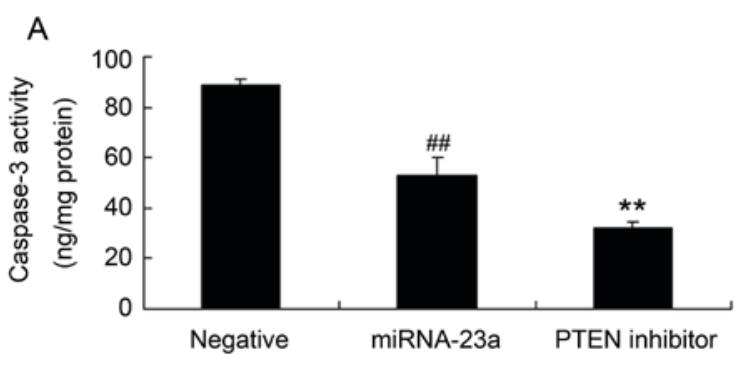

C

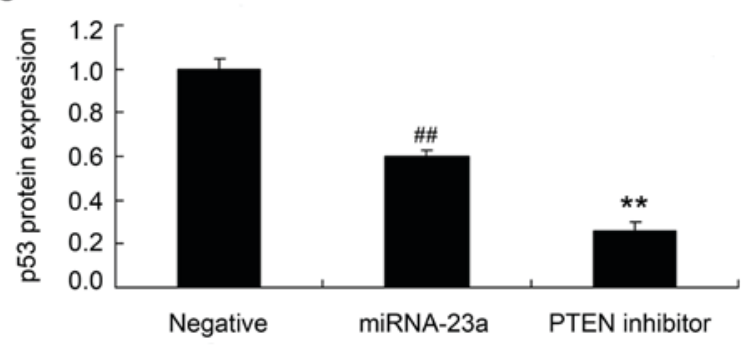

B

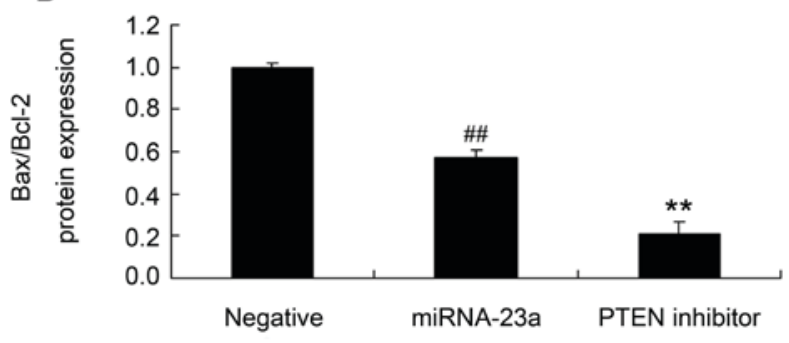

$\mathrm{D}$

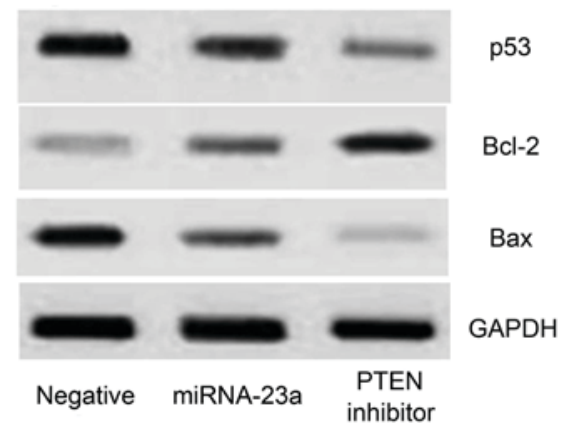

Figure 7. Effects of a PTEN inhibitor on apoptosis in an in vitro model of AMI. Effects of a PTEN inhibitor on (A) caspase-3 activity, (B) Bax/Bcl-2 protein expression ratio and (C) p53 protein expression. (D) Representative western blot images for Bax, Bcl-2 and p53 protein expression in an in vitro model of AMI. ${ }^{\# \#} \mathrm{P}<0.01$ vs. negative control group; ${ }^{* *} \mathrm{P}<0.01$ vs. miRNA-23a group. PTEN, phosphatase and tensin homolog; AMI, acute myocardial infarction; Bax, Bcl-2-associated X; p53, tumor suppressor p53; miRNA, microRNA.

China and worldwide have been initiated using clinical and animal experimental models. In the present study, miRNA-23a expression in patients with AMI was demonstrated to be downregulated compared with the healthy volunteer group. Mao et al (21) identified miRNA-23a as being involved in tumor necrosis factor- $\alpha$-induced protection of bone marrow-derived mesenchymal stem cell apoptosis through regulating caspase-7 and myocardial infarction.

A previous study demonstrated that oxidative stress is a common mechanism of various factors that cause cardiovascular injury (22). During the pathological process of a number of cardiovascular diseases, including atherosclerosis, hypertension, ischemic heart disease and hyperlipidemia, excessive oxygen free radical production and suppression of the antioxidant defense mechanism for managing free radicals has been observed (22). Previously, attention has focused on the influence of reactive oxygen species (including oxygen free radicals) on cardiac and vascular function. White blood cells produce reactive oxygen species, which cause vascular injury in AMI (23). White blood cells have the ability to release high 
concentrations of reactive oxygen species, which kill bacteria and result in vascular injury (8). In addition, AMI also leads to the production of reactive oxygen species, therefore causing tissue damage during reperfusion, including in the heart, brain and liver. It has been reported that reactive oxygen species are essential not only in pathological processes, but also in normal signaling pathways and physiological mechanisms (24). In accordance with this, the present study demonstrated that overexpression of miRNA-23a significantly increased the activity of SOD, GSH and CAT, and inhibited MDA levels, in $\mathrm{H}_{2} \mathrm{O}_{2}$-treated $\mathrm{H} 9 \mathrm{C} 2$ cells. Zhao et al (25) demonstrated that miRNA-23a-3p attenuated injury caused by oxidative stress in focal cerebral ischemia-reperfusion mice.

miRNA-23a-3p inhibits the infarction factors that kill the myocardial cells of rats, including the expression of p53, Bax and tumor necrosis factor receptor superfamily member 6 (Fas). Cytochrome $\mathrm{C}$ is released and forms an apoptotic body by combining with caspase-9 (26). Subsequently, apoptosis is induced in cells with activated caspase-3 through downstream signaling pathways (27). Studies have demonstrated that caspase- 3 and caspase- 9 proteases effectively inhibited the apoptosis of cardiac muscle cells by decreasing the activity and expression of caspase-3/9 (28). The Bcl-2 family is reported to affect the release of cytochrome $\mathrm{C}$ through mitochondrial channels, inhibit the release of Bax and inhibit the activation of cytochrome C-induced apoptosis. Therefore, Bcl-2 acts as an inhibitor of apoptosis (26).

Fluctuations in the intracellular content of Bcl-2 can induce a pro-apoptotic signaling cascade (29). Bcl-2 family members are among the most important membrane protein molecules in apoptosis and control cell apoptosis by internal and external signals in different cells (29). A number of studies have demonstrated that certain genes promote apoptosis (such as Bax, p53 and Fas), while other genes are able to inhibit apoptosis (such as Bcl-2) (30). The in vivo ratio between proapoptotic proteins and inhibitory proteins is key for determining the fate of cells (29). For instance, when Bcl-2 protein expression is higher than Bax protein expression, cell survival is promoted. By contrast, when Bax protein levels are higher compared with Bcl-2 levels, apoptosis is accelerated (26). Therefore, the results of the present study demonstrated that overexpression of miRNA-23a decreased caspase- 3 activity, Bax/Bcl-2 ratio and $\mathrm{p} 53$ protein expression in $\mathrm{H} 9 \mathrm{C} 2$ cells treated with $\mathrm{H}_{2} \mathrm{O}_{2}$. Wang et al (31) revealed that berberine induced tumor apoptosis through upregulation of p53 by miRNA-23a in hepatocellular carcinoma. Wang et al (32) also reported that glucagon like peptide-1 reduced apoptosis and Bax expression by downregulating miRNA-23a.

PTEN is a non-secreted protein inherently expressed in cells. It also exists in the nucleus, cytoplasm and membrane (10). It is involved in multiple signal transduction pathways within a cell, including those associated with cell division, proliferation, differentiation, migration and extracellular matrix metabolism, and other physiological and pathological processes (9). In the present study, the PTEN inhibitor was observed to increase miRNA-23a expression in $\mathrm{H} 9 \mathrm{C} 2$ cells treated with $\mathrm{H}_{2} \mathrm{O}_{2}$. Tian et al (33) demonstrated that miRNA-23a enhanced migration and invasion in osteosarcoma cells through downregulation of PTEN expression.

PTEN also serves an important role in growth (9). In addition, PTEN regulates developmental malformations and abnormal differentiation in the third germ layer (34). Investigation of the effect of PTEN on heart growth and function in adult mice with a specific knockout of PTEN in cardiac muscle cells demonstrated that muscular hypertrophy caused by external pressure may be inhibited by knocking out PTEN, which therefore protects the heart functions (35). In the present study, the downregulation of PTEN was observed to suppress p53 protein expression in miRNA-23a-overexpressing $\mathrm{H} 9 \mathrm{C} 2$ cells treated with $\mathrm{H}_{2} \mathrm{O}_{2}$.

In summary, the present study has confirmed that the expression of miRNA-23a may regulate AMI-induced apoptosis in patients with AMI and an in vitro model, which may occur via inhibition of caspase-3, Bax/Bcl-2 and p53 expression through targeting PTEN. The results of the present study indicate that PTEN/miRNA-23a may be potential therapeutic targets for treating AMI-induced apoptosis in a clinical setting.

\section{Acknowledgements}

Not applicable.

\section{Funding}

The present study was supported by the National Natural Science Foundation of China (grant no. 81560368).

\section{Availability of data and materials}

The analysed data sets generated during the study are available from the corresponding author on reasonable request.

\section{Authors' contributions}

QS designed the study; SL and JR performed the experiments; QS analyzed the data; QS wrote the manuscript.

\section{Ethics approval and consent to participate}

The present study was approved by the Regional Ethics Committee of Beijing Chaoyang Hospital (Beijing, China) and all patients involved provided written informed consent.

\section{Consent for publication}

Not applicable.

\section{Competing interests}

The authors declare that they have no competing interests.

\section{References}

1. Vavalle JP, van Diepen S, Clare RM, Hochman JS, Weaver WD, Mehta RH, Pieper KS, Patel MR, Patel UD, Armstrong PW, et al: Renal failure in patients with ST-segment elevation acute myocardial infarction treated with primary percutaneous coronary intervention: Predictors, clinical and angiographic features, and outcomes. Am Heart J 173: 57-66, 2016.

2. Husebye T, Eritsland J, Müller C, Sandvik L, Arnesen H, Seljeflot I, Mangschau A, Bjørnerheim R and Andersen GØ: Levosimendan in acute heart failure following primary percutaneous coronary intervention-treated acute ST-elevation myocardial infarction. Results from the LEAF trial: A randomized, placebo-controlled study. Eur J Heart Fail 15: 565-572, 2013. 
3. Herrmann J, Gersh BJ, Goldfinger JZ, Witzenbichler B, Guagliumi G, Dudek D, Kornowski R, Brener SJ, Parise H, Fahy M, et al: Body mass index and acute and long-term outcomes after acute myocardial infarction (from the harmonizing outcomes with revascularization and stents in acute myocardial infarction trial). Am J Cardiol 114: 9-16, 2014.

4. Wang ZF, Wang NP, Harmouche S, Philip T, Pang XF, Bai F and Zhao ZQ: Postconditioning promotes the cardiac repair through balancing collagen degradation and synthesis after myocardia infarction in rats. Basic Res Cardiol 108: 318, 2013.

5. Huang CC, Wei HJ, Lin KJ, Lin WW, Wang CW, Pan WY, Hwang SM, Chang Y and Sung HW: Multimodality noninvasive imaging for assessing therapeutic effects of exogenously transplanted cell aggregates capable of angiogenesis on acute myocardial infarction. Biomaterials 73: 12-22, 2015.

6. Zhang YJ, Yang SH, Li MH, Iqbal J, Bourantas CV, Mi QY, Yu YH, Li JJ, Zhao SL, Tian NL and Chen SL: Berberine attenuates adverse left ventricular remodeling and cardiac dysfunction after acute myocardial infarction in rats: Role of autophagy. Clin Exp Pharmacol Physiol 41: 995-1002, 2014

7. Fraccarollo D, Galuppo P, Neuser J, Bauersachs J and Widder JD Pentaerythritol tetranitrate targeting myocardial reactive oxygen species production improves left ventricular remodeling and function in rats with ischemic heart failure. Hypertension 66 : 978-987, 2015.

8. Nedoboy PE, Morgan PE, Mocatta TJ, Richards AM, Winterbourn CC and Davies MJ: High plasma thiocyanate levels are associated with enhanced myeloperoxidase-induced thiol oxidation and long-term survival in subjects following a first myocardial infarction. Free Radic Res 48: 1256-1266, 2014.

9. Yang X, Qin Y, Shao S, Yu Y, Zhang C, Dong H, Lv G and Dong S: MicroRNA-214 inhibits left ventricular remodeling in an acute myocardial infarction rat model by suppressing cellular apoptosis via the phosphatase and tensin homolog (PTEN). Int Heart J 57: 247-250, 2016.

10. Xue R, Lei S, Xia ZY, Wu Y, Meng Q, Zhan L, Su W, Liu H, Xu J, Liu Z, et al: Selective inhibition of PTEN preserves ischaemic post-conditioning cardioprotection in STZ-induced Type 1 diabetic rats: Role of the PI3K/Akt and JAK2/STAT3 pathways. Clin Sci (Lond) 130: 377-392, 2016

11. Parajuli N, Yuan Y, Zheng X, Bedja D and Cai ZP: Phosphatase PTEN is critically involved in post-myocardial infarction remodeling through the Akt/interleukin-10 signaling pathway. Basic Res Cardiol 107: 248, 2012.

12. Boon RA and Dimmeler S: MicroRNAs in myocardial infarction. Nat Rev Cardiol 12: 135-142, 2015.

13. Shi H, Zhang G, Wang J, Wang Z, Liu X, Cheng L and Li W: Studying dynamic features in myocardial infarction progression by integrating miRNA-transcription factor co-regulatory networks and time-series RNA expression data from peripheral blood mononuclear cells. PLoS One 11: e0158638, 2016.

14. Livak KJ and Schmittgen TD: Analysis of relative gene expression data using real-time quantitative PCR and the 2(-Delta Delta C(T)) method. Methods 25: 402-408, 2001.

15. Yano H, Hibi K, Nozawa N, Ozaki H, Kusama I, Ebina T, Kosuge M, Tsukahara K, Okuda J, Morita S, et al: Effects of valsartan, an angiotensin II receptor blocker, on coronary atherosclerosis in patients with acute myocardial infarction who receive an angiotensin-converting enzyme inhibitor. Circ J 76 : 1442-1451, 2012.

16. Räber L, Kelbæk H, Taniwaki M, Ostojic M, Heg D, Baumbach A, von Birgelen C, Roffi M, Tüller D, Engstrøm T, et al: Biolimus-eluting stents with biodegradable polymer versus bare-metal stents in acute myocardial infarction: Two-year clinical results of the COMFORTABLE AMI trial. Circ Cardiovasc Interv 7: 355-364, 2014

17. Liu Y, Chen JY, Huo Y, Ge JB, Xian Y, Duan CY, Chen SQ, Jiang W, Chen PY and Tan N; RESCIND group: Aggressive hydraTion in patients with ST-Elevation Myocardial infarction undergoing Primary percutaneous coronary intervention to prevenT contrast-induced nephropathy (ATTEMPT): Study design and protocol for the randomized, controlled trial, the ATTEMPT, RESCIND 1 (First study for REduction of contraSt-induCed nephropathy followINg carDiac catheterization) trial. Am Heart J 172: 88-95, 2016.
18. Hofsten DE, Kelbaek H, Helqvist S, Kløvgaard L, Holmvang L, Clemmensen P, Torp-Pedersen C, Tilsted HH, B $\varnothing$ tker HE, Jensen LO, et al: The third DANish study of optimal acute treatment of patients with ST-segment Elevation Myocardial infarction: Ischemic postconditioning or deferred stent implantation versus conventional primary angioplasty and complete revascularization versus treatment of culprit lesion only: Rationale and design of the DANAMI 3 trial program. Am Heart J 169: 613-621, 2015 .

19. Bronze-da-Rocha E: MicroRNAs expression profiles in cardiovascular diseases. Biomed Res Int 2014: 985408, 2014.

20. Matsumoto S, Sakata Y, Nakatani D, Suna S, Mizuno H, Shimizu M, Usami M, Sasaki T, Sato H Kawahara Y, et al: A subset of circulating microRNAs are predictive for cardiac death after discharge for acute myocardial infarction. Biochem Biophys Res Commun 427: 280-284, 2012.

21. Mao J, Lv Z and Zhuang Y: MicroRNA-23a is involved in tumor necrosis factor-alpha induced apoptosis in mesenchymal stem cells and myocardial infarction. Exp Mol Pathol 97: 23-30, 2014.

22. Kim SJ, Kuklov A and Crystal GJ: In vivo gene delivery of XIAP protects against myocardial apoptosis and infarction following ischemia/reperfusion in conscious rabbits. Life Sci 88: 572-577, 2011

23. Mei B, Wang T, Wang Y, Xia Z, Irwin MG and Wong GT: High dose remifentanil increases myocardial oxidative stress and compromises remifentanil infarct-sparing effects in rats. Eur J Pharmacol 718: 484-492, 2013.

24. Hazini A, Cemek M, Isildak I, Alpdağtas S, Önül A, Senel Ü, Kocaman T, Dur A, Iraz M and Uyarel $\mathrm{H}$ : Investigation of ischemia modified albumin, oxidant and antioxidant markers in acute myocardial infarction. Postepy Kardiol Interwencyjnej 11: 298-303, 2015.

25. Zhao H, Tao Z, Wang R, Liu P, Yan F, Li J, Zhang C, Ji X and Luo Y: MicroRNA-23a-3p attenuates oxidative stress injury in a mouse model of focal cerebral ischemia-reperfusion. Brain Res 1592: 65-72, 2014.

26. Li R, Geng HH, Xiao J, Qin XT, Wang F, Xing JH, Xia YF, Mao Y, Liang JW and Ji XP: miR-7a/b attenuates post-myocardial infarction remodeling and protects $\mathrm{H} 9 \mathrm{c} 2$ cardiomyoblast against hypoxia-induced apoptosis involving Sp1 and PARP-1. Sci Rep 6: 29082, 2016.

27. Ham O, Lee SY, Lee CY, Park JH, Lee J, Seo HH, Cha MJ, Choi E, Kim S and Hwang KC: let-7b suppresses apoptosis and autophagy of human mesenchymal stem cells transplanted into ischemia/reperfusion injured heart 7 by targeting caspase- 3 . Stem Cell Res Ther 6: 147, 2015.

28. Agosto M, Azrin M, Singh K, Jaffe AS and Liang BT: Serum caspase-3 p17 fragment is elevated in patients with ST-segment elevation myocardial infarction: A novel observation. J Am Coll Cardiol 57: 220-221, 2011

29. Luo KQ, Long HB and Xu BC: Reduced apoptosis after acute myocardial infarction by simvastatin. Cell Biochem Biophys 71: 735-740, 2015.

30. Boyle AJ, Hwang J, Ye J, Shih H, Jun K, Zhang Y, Fang Q, Sievers R, Yeghiazarians Y and Lee RJ: The effects of aging on apoptosis following myocardial infarction. Cardiovase Ther 31: e102-e110, 2013.

31. Wang N, Zhu M, Wang X, Tan HY, Tsao SW and Feng Y: Berberine-induced tumor suppressor p53 up-regulation gets involved in the regulatory network of MIR-23a in hepatocellular carcinoma. Biochim Biophys Acta 1839: 849-857, 2014.

32. Wang C, Li Q, Wang W, Guo L, Guo C, Sun Y and Zhang J: GLP-1 contributes to increases in PGC-1 $\alpha$ expression by downregulating miR-23a to reduce apoptosis. Biochem Biophys Res Commun 466: 33-39, 2015.

33. Tian K, Di R and Wang L: MicroRNA-23a enhances migration and invasion through PTEN in osteosarcoma. Cancer Gene Ther 22: 351-359, 2015.

34. Li CM, Shen SW, Wang T and Zhang XH: Myocardial ischemic post-conditioning attenuates ischemia reperfusion injury via PTEN/Akt signal pathway. Int J Clin Exp Med 8: 15801-15807, 2015.

35. Keyes KT, $\mathrm{Xu}$ J, Long $\mathrm{B}$, Zhang $\mathrm{C}, \mathrm{Hu} \mathrm{Z}$ and $\mathrm{Ye} \mathrm{Y}$ : Pharmacological inhibition of PTEN limits myocardial infarct size and improves left ventricular function postinfarction. Am J Physiol Heart Circ Physiol 298: H1198-H1208, 2010. 